|| ISSN(online): 2589-8698 || ISSN(print): 2589-868X ||

International Journal of Medical and Biomedical Studies

Available Online at www.ijmbs.info

NLM (National Library of Medicine ID: 101738825)

Index Copernicus Value 2018: 75.71

Volume 4, Issue 8; August: 2020; Page No. 09-10

Original Research Article

\title{
SPECTRUM OF BLUNT ABDOMINAL TRAUMA
}

Dr. Ajay Pal ${ }^{1}$, Dr. Indira ${ }^{2}$, Dr. L. K. Kapil ${ }^{3}$

${ }^{1}$ Department of General Surgery,S.P. Medical College \& Associated group of Hospitals, Bikaner

2 Department of Pediatrics,S.P. Medical College and P.B.M.,Associated Group of Hospitals, Bikaner

${ }^{3}$ Trauma center, PBM Hospital, Bikaner

Article Info: Received 28 June 2020; Accepted 27 July 2020

DOI: https://doi.org/10.32553/ijmbs.v4i8.1331

Corresponding author: Dr. Indira

Conflict of interest: No conflict of interest.

\section{Abstract}

Background: Blunt abdominal trauma is a leading cause of morbidity and mortality among all age groups. Many injuries may not manifest during the initial assessment and treatment period.

Methods: Hospital based cross-sectional study conducted at Trauma center and P.B.M Hospital, Bikaner

Results: Distribution according to type of injury consisted of maximum cases, $86 \%$ of road traffic accidents 74 of which were male and 12 female. $10 \%$ cases were of fall from height, 6 were male and 4 female .Assault cases were $4 \%$. Case distribution according to organ involved consisted of $54.00 \%$ cases of liver injury, $18.00 \%$ cases were of splenic injury, $23.00 \%$ patients had ilial injury, Pancreatic injury occurred in 2 patient.

Conclusions: Males were pre-dominantly affected. Road traffic accident was the most common cause of injury. Though conservative management is successful in carefully selected patients, operative management remains the main stay of treatment.

Keywords: Blunt abdominal trauma, Liver injury, Perforation, Splenic injury

\section{Introduction}

Blunt injury of abdomen is also a result of fall from height, assault with blunt objects, sport injuries, industrial mishaps, bomb blast and fall from riding bicycle ${ }^{1}$. Blunt abdominal trauma is usually not obvious. Hence, often missed, unless, repeatedly looked for. Due to the inadequate treatment of the abdominal injuries, most of the cases are fatal. The knowledge in the management of blunt abdominal trauma has progressively increasing due to the in-patient data gathered from different parts of the world. In spite of the best techniques and advances in diagnostic and supportive care, the morbidity and mortality remains high. The reason for this could be due to the interval between trauma and hospitalization, delay in diagnosis, inadequate and lack of appropriate surgical treatment, postoperative complications and associated trauma especially to head, thorax and extremities. ${ }^{2}$

The relatively fixed position of the liver and its large size makes it more prone for injury in blunt trauma of the abdomen. Liver and spleen together, account for $75 \%$ of injuries in blunt abdominal trauma ${ }^{2}$. Though liver is the second most commonly injured organ in abdominal trauma, it is the most common cause of death following abdominal injury. Compared to splenic injuries, management of liver trauma still remains a challenge in the best of trauma centers.

Materials \& Method
Study design: Hospital based cross-sectional study.

Study place: Dept. of Trauma center and P.B.M Hospital, Bikaner

Inclusion Criteria: Patients admitted with history of blunt trauma abdomen due to road traffic accidents, accidental falls, and trauma by blunt objects and assault attending to P.B.M Hospital, Bikaner

\section{Exclusion criteria:}

- Associated Orthopaedic Injuries

- Associated With Severe Head Injury

- Associated With Severe Chest Injury

- Pregnancy

\section{Data analysis:}

Data was recorded on a Performa. The data analysis was computer based; SPSS-22 was used for analysis. For categoric variables chi-square test will be used. For continuous variables independent samples's $t$-test was used. $p$-value $<0.05$ was considered as significanit.

Results

Table 1: Type of Injury

\begin{tabular}{llll}
\hline Type of Injury & Male & Female & Total \\
\hline RTA & 74 & 12 & 86 \\
\hline FFH & 6 & 4 & 10 \\
\hline Assault & 3 & 1 & 4 \\
\hline Others & 0 & 0 & 0 \\
\hline
\end{tabular}


Distribution according to type of injury consisted of maximum cases, $86 \%$ of road traffic accidents 74 of which were male and 12 female. $10 \%$ cases were of fall from height, 6 were male and 4 female .Assault cases were $4 \%$. There were no cases of other injuries causing blunt trauma abdomen such as bomb blast injuries, cyclist injuries, sports injuries etc.

Table 2: Organ Involved in Injury

\begin{tabular}{ll}
\hline Organ Involved & Total \\
\hline Liver & 54 \\
\hline Spleen & 36 \\
\hline Intestine & 23 \\
\hline Pancreas & 2 \\
\hline Kidney & 4 \\
\hline Urinanry Bladder & 2 \\
\hline Mesentry & 5 \\
\hline Diaphragm & 1 \\
\hline
\end{tabular}

Case distribution according to organ involved consisted of $54.00 \%$ cases of liver injury, $18.00 \%$ cases were of splenic injury, $23.00 \%$ patients had ilial injury, Pancreatic injury occurred in 2 patient.

Table 3: Management

\begin{tabular}{ll}
\hline Management & Total \\
\hline Conservative & 76 \\
\hline Operative & 24 \\
\hline
\end{tabular}

Based on the type of management done cases were divided as operative and conservative. Operative management was done in 24 patients and 76 patients were managed conservatively

\section{Discussion}

Distribution according to type of injury consisted of maximum cases, $86 \%$ of road traffic accidents 74 of which were male and 12 female. $10 \%$ cases were of fall from height, 6 were male and 4 female. Assault cases were $4 \%$. There were no cases of other injuries causing blunt trauma abdomen such as bomb blast injuries, cyclist injuries, sports injuries etc.

Madhumita Mukhopadhyay et al in their study of 47 patients who underwent laparotomy following intestinal injuries from blunt abdominal trauma over a period of 4 years found that the $M: F$ ratio in this study was $8.4: 1^{3}$ Similarly John $\mathrm{L}$ Kendall et al in a retrospective cohort study of 1169 cases of BAT reported that $66 \%$ of the affected individuals were Males ${ }^{4}$

Similar Findings were reported by Khanna et al who found that $t$ most common mode of injury in cases of BAT was Road Traffic accidents (57\%). In contrast to our study
Khanna et al in their study found assault (33\%) to be more common than fall from height $(15 \%)^{5}$

Case distribution according to organ involved consisted of $54.00 \%$ cases of liver injury, $18.00 \%$ cases were of splenic injury, $23.00 \%$ patients had ilial injury, Pancreatic injury occurred in 2patient.Similar study by Cox et al showed splenic and hepatic injuries in $46 \%$ and $33 \%$ patients respectively ${ }^{6}$

There is an increase in trend towards conservative management if the patient is haemodynamically stable. The grade of injury was assessed by USG and CECT and was most of the time managed conservatively. Minor lacerations and capsular tears which are difficult to diagnose clinically can be easily demonstrated in USG and CECT scan and were selected for non-operative management. However the disadvantage of non-operative management is missed injuries resulting in increased morbidity and mortality. Operative intervention is needed in hemodynamically unstable patients who are not responding to aggressive fluid resuscitation and those with significant organ injuries. The common surgeries performed in our patients included splenectomy, primary closure of perforation and resection and anastomosis. Similar surgeries were required in patients of BAT as reported by $\mathrm{Wu} C L$ et al $A B^{7}$

\section{Conclusion}

Blunt Abdominal Trauma is one of the important causes of morbidity and mortality in relatively young individuals. Most common mode of injury is road traffic accidents and men are affected predominantly

\section{References}

1. Sabiston's Textbook of surgery:18th edition: vol 1: 2008: p501519.

2. Starling SV, Drumond DAF. Tratamento não operatório de 1.768 pacientes portadores de lesões das vísceras maciças abdominais por trauma contuso atendidos no Hospital João XXIII. Rev Med Minas Gerais. 2014;24(4):432-40.

3. Kendall JL, Kestler AM, Whitaker KT, Adkisson M-M, Haukoos JS. Blunt Abdominal Trauma Patients Are at Very Low Risk for IntraAbdominal Injury after Emergency Department Observation. Western Journal of Emergency Medicine. 2011;12:496-504.

4. Joe Jack Davis, Isidore Cohn, Francis C. Nance; Diagnosis and management of Blunt abdominal trauma. Ann, Surg, 1976 183: 672-678.

5. R. Khanna, S Khanna, P Singh, Puneet and A K Khanna;Spectrum of blunt abdominal trauma in Varanasi; Quart J; 1999:35;25-28

6. Cox, Everard F. Blunt abdominal trauma: A 5 year Analysis of 870 patients requiring Celiotomy; Ann, Surg 1984;199:467-474.

7. $\mathrm{Wu} C \mathrm{C}, \mathrm{Chou} \mathrm{MC}$. Surgical management of blunt abdominal trauma. Gaoxiong Yi Xue Ke Xue Za Zhi. 1993;9:540-52 